\title{
MANAGERIAL PERSPECTIVE ON ETHICAL CULTURE IN ORGANIZATIONS AND INSTITUTIONS
}

\author{
Claudia Pau ${ }^{1 *}$, Mihaela Martin ${ }^{1}$, Jeanina Ciurea ${ }^{2}$ \\ ${ }^{1}$ UBB Center from Reșița, Faculty of Political, Administrative and Communication Sciences \\ ${ }^{2}$ UBB Center from Resita, Faculty of Economics and Business Management \\ Traian Vuia Square, no.1-4, Reșiţa, Caraș-Severin, România \\ * Corresponding author. E-mail: claudia.pau@ubbcluj.ro
}

\begin{abstract}
Ethical performance aims to analyze the different dimensions of an ethical performance framework in a global context, then illustrate how public or private organizations measure ethical performance. In order to achieve this goal, a number of performance-enhancing factors are needed, which however are many, complex, interrelated, and sometimes difficult to measure. Trends show an increase in performance regimes, audit, and inspection for public agencies along with numerous attempts to measure ethical performance.
\end{abstract}

Keywords: ethics, performance, tools, audit, organization, culture.

\section{Introduction}

Most of the public services are dominated by performance measurement and management regimes and the development of key performance indicators too. Civil servants were subject to the regimes of performance as part of their own development and as part of the organizations-wide regimes expected to demonstrate the efficiency, effectiveness, responsiveness, and so on. Such developments are part of the impulse of the accountability of spending on taxpayers' money. The motors of performance improvement are numerous and complex, and it is not always clear what impact individuals drivers or the combination of different factors over performance results have.

A key question is what the organization can do to facilitate ethical behavior. One, under research, is how the organizations could recognize the value of dissidence in organizations and create channels through which this dissidence could be expressed [5]. This is not just the introduction of warning procedures, but the way in which an organization can learn from different opinions, avoiding the dangers of "group thinking" if accepted standards and conventions are in the way of critical thinking. It takes courage to stand against accepted organizational wisdom, and a key role for managers is to support staff who want to disagree, provided, of course, that such dissidence is governed by organizational and public interests and not by personal interests.

\subsection{The Ethical Health of an Organization}

The concept of organizational ethical performance is quite confusing, so we are rhetorically asking ourselves the question, how an organization ethical health can be measured. Indeed how can we define the ethical organization? Is it the sum of the quality of the individual acts carried by the members of an organization, the existence of an ethical culture, whatever it is defined or the extent to which an organization fulfills its social and community obligations? These are not abstract questions. Organizations are increasingly being assessed relative to a certain measure of ethical performance. This raises a number of issues and in this chapter we explore legal, managerial, technical, and implementation issues associated to the notion of ethical performance, all of which are linked to each other.

Several interested parties have different performance expectations and it is difficult to catch all the interested parties' interests in an agreed concrete performance scheme. Ethics issues in public service organizations are influenced by a mixture of people, reasons, organizational imperative and values of society. Trends in ethics have moved from relying on individual integrity to concrete systems of conformity. Unfortunately, we do not have enough evidence of research to argue that an ethical leadership, code of conduct or actual employees' training will have the greatest impact and we also we do not know the impact of regulation and external inspection over the organization's collectivity and specificity. The ethical audit should reflect both individual performance and the specific organizational framework in which the employees work. But, how do we know if we are doing the right thing and how can we improve?

This issue is related to the type of performance, because it is particularly important for public service organization and civil servants, because they spend taxpayers' money. The objectives of public sector organizations are not always clear, they are often 
ambiguous or, indeed, may be in conflict. A performance system can be multipurpose and can meet the needs of different interested parties. For instance, Behn [2] identifies a number of functions for the performance of public service organizations: assessment, which focuses on the organization's performance, monitoring, concerned with ensuring that the staff do the right thing, the staff's motivation to do the right thing, for instance, to improve integrity and fight corruption, promotion which demonstrates the belief of political superiors, legislators, interested parties, journalists and citizens that the organization is doing a good job, celebrating success - an important organizational ritual, learning - which focuses on policies or practices which work and permanent improvement and adapting to new, continuous concern to improve performance.

We can only measure what people are doing, not what they say they are doing or how they have been reported, because we cannot measure their intentions. This point has a particular relevance, considering that unethical results often result from a lack of knowledge or incompetence, rather than by a bad intention. Similarly, it is a concern about the ethical standards related to the strategy as part of what the organization represents or are labeled and considered to impede important financial considerations.

\subsection{Factors Influencing Performance}

\section{Development}

Measuring public service performance is generally difficult. External factors influence the performance of the public service and they, by definition, are also the more distant from the control that can be exercised by the organization itself. Not only that, but those variables over which the organization can have a certain control, such as leadership, innovation, even strategy do not show the same consistent pattern of improvement [1]. Similarly to ethical performance, we do not have enough evidence of research to argue that ethical leadership or a code of conduct or training will have the greatest impact. We also do not know the impact of regulation and external inspection.

However why should be a greater concern about ethics and why now?

There are a number of different developments brought together under the umbrella of ethics. One development is the perceived failure of the traditional accountability mechanisms, so as to remain pockets of corrupt practices within the public services (for instance, the United Kingdom parliamentary expenses scandals). Secondly, as part of "the audit explosion" there is a political agenda and the mechanism put in place to develop an ethical framework must demonstrate their effectiveness. A third development is the rise in international concerns about fraud and widespread corruption.
Whether the solution is the ethical audit or ethical review, as we prefer, then we must recognize that a thin interpretation will not be enough. The review should not be a task, but more, for instance technical, political, managerial, and ethical which are part of a broader ethical framework including awareness training, ethical guidelines, and ethical decision trees. Ethical audit should reflect both individual performance and organizational setting and should comprise a number of different parts, including: prevention and anti-corruption measures; statements of values for the organization to have high aspirations; ethics awareness training, staff issues regarding recruitment, promotion and assessment, leadership issues, relationship issues on public confidence, for example, etc.

\section{Dimensions of the Ethical Leadership of an Organization}

Ethical leadership is a multidimensional concept distinct from other management styles consisting of "moral person"," moral manager" and "a positive leaderadept relationship".

Several theories, such as the theory of cognitive moral development, the theory of social learning, the theory of consolidation, and the theory of social exchange explain the role leaders play in organizations regarding ethics and integrity.

To build a reputation for ethical leader, both the moral person and the moral manager should be equally powerful. Public sector leaders often underestimate the latter and therefore they risk being perceived a neutral ethical leaders.

Ethical leadership contributes to an ethical climate and many other positive organizational results and although it seems to be a good overall strategy for leadership, it is not a panacea.

Ethical leadership can be considered as a general concept of variation; while the basic components of ethical leadership - moral person, moral manager, positive lead-follower relationship - can be quite consistent between different types of organizations, the way these components are interpreted and adapted may differ, the same goes for the relative weight that people grant to the components in question. Ethical leadership in practice may depend on the organizational, cultural or social context. Ethical leadership is not exclusively reserved for managers; it could therefore be found at all levels within an organization.

But why and how are leaders important for organizational ethics? Because employees will imitate their supervisors and they will learn what to do and what not to do, by observing their leaders' behavior. Somewhat different, the theory of reinforcement suggests that an individual behavior represents the result of its prospective consequences, for example, leaders can lead employees' behavior through specific rewards and punishments [7]. Moreover, by doing so, the employees themselves 
become models for other employees whose behavior leaders either reward or punish.

The theory of social exchange, on the other hand, claims that the ethical behavior of the followers is influenced by the quality of the interpersonal treatment that employees receive from leaders; the better the treatment, more employees feel obliged to respond to positive behavior [3], [7].

To investigate the significance of ethical leadership, Ciulla [4] proposes that management ethics be examined through five interlinked dimensions: ethics of a leader as a person; ethics of a leadership/follower relationship; leadership ethics; ethics of what a leader does or does not do; leadership in the wider community context.

The organizational results of ethical leadership consist of less unethical behavior of employees, employees will have a higher level of ethical reasoning, favoring an ethical organizational climate that will make employees feel that their work is more significant, they have more control over their work, with more initiative, willing to put in an extra effort.

This makes the employees more altruistic and shows more willingness to help others in work-related issues, the organizational citizenship behavior is being enhanced, feeling more committed to work, becoming less uncertain, with a more optimistic view of the future. Consequently, it succeeds cultivating trust and reducing interpersonal conflicts between colleagues through a larger identification and commitment to the organization. And can we ask ourselves what the expectations of ethical leadership of these different leaders are? Should everyone behave the same or our expectations differ regarding how they will behave? Is a political leader allowed, for instance, not to be ethical in the political arena? What kind of leader do you expect to be the best moral manager? Do you believe that all the convictions and expectations of ethical leadership of public sector employees in (ex.) India are the same as those of employees from Belgium or Australia?

Managers, individuals and organizations have a role to play in cultivating ethics and integrity through ethical leadership. This also includes our own role, and ethics must be at the forefront of our attention and to start by giving a good example to others from our business environment.

\section{Political and Legal Instruments for Measuring the Organizational Culture}

An impressive number of studies per country have introduced us a wide range of policy and legal instruments used, for example to fight corruption or to sustain standards of conduct by coding. However, the extent to which we have learned from each other or the extent to which a universal theory has been developed, shall we say, remains a questionable point. Furthermore, cultural relativism considers that behavior is determined by its cultural context and as such, there is no final or correct way of behaving. Consequently, no culture can claim superiority, because the rules, values and practices in the cultural context determine what is right or wrong. This vision can be contrasted with the ethical universality which claims that we can determine what is good or bad, because there are specific absolute truths that apply everywhere, and universal values transcend cultures. The issue regarding this latter approach is that it represents a short step toward ethical imperialism which tries to judge others according to our own standards and to impose these standards to others.

Informal processes will work through myths and stories passed from a generation of staff to another, through group rules and practices which bypass formal working arrangements. Thus, introducing service-level agreements between departments of the same local authority or municipality can undermine informal arrangements to help a colleague elsewhere, understanding that at some point the favor will be returned. Which way of working is more efficient? Are developing countries committed to ethical reforms? Cultures are dynamic and we should anticipate the existence of subcultures within organizations. It may be neither desirable nor feasible to build a strong and unified feeling of values. Culture is undoubtedly an evasive concept and the extent to which it can be managed will remain contested. According to many researches, compliance approaches could be counterproductive, because they underline the avoidance of punishments instead of promoting self-government. Ethics is defined in accordance with the law rather than in ethical aspirations and implicitly support a code of moral mediocrity [6]. In practice, relying solely on the application of anticorruption cannot lead to success, because countries have increasingly focused on institutionalized integrity management, relying more on preventive measures, e.g. China. The approach to integrity reflects an opposite view of organizational ethics. The programs within this kind of approach aim to define the organizational (moral) values and encourage the employees' commitment to act according to these core values and ethical aspirations [7]. An approach to integrity is based on the concept of employee self-government in accordance with a set of guidelines within the organization and the environment.

Until now it is clear that approaches to compliance and integrity have different guidelines on underlying ethics, objectives and behavioral assumptions. Also, in both approaches a wide range of policies, methods and tools to choose from is available. In the literature, external and internal controls are distinguished, which can be used to encourage a responsible behavior within organizations. External controls are required, top-down instruments to lead the ethical conduct of employees, such as laws, rules and codes, as well as monitoring and strengthening these rules by penalizing those who commit mistakes.

Policy instruments are the tools used to achieve the policy objectives such codes of conduct or an anti- 
corruption agency. Policy implementation, which is crucial, will depend on leadership and the role of key individuals and resources, and the adequate resources. The policy styles addressed will reflect the extent of the central direction or local discretion and will address how policy responses are formulated.

Guidelines and sanctions can take a number of different forms enshrined in rules, regulations, status and codes of ethics. Sometimes it happens that those codes of ethics, which refer to the ethical conduct of civil servants and codes of conducts, which have a broader scope to cover a wide range of employee organizational practices and conduct practices.

However, it is generally considered that, despite of the proliferation of codes of ethics for both public sector of organizations, as well as for private ones, codes are a necessary tool, but not enough to facilitate ethical behavior.

Thus, although we generally agree with the opinion that codes are necessary but not sufficient, we advocate that an analysis of the context, content, implementation and application of the codes can increase their effectiveness, by adopting a privileged perspective.

\section{Conclusion}

Ethically, individual values, organizational values, and broader social values will get mix up. It is obvious, more and more that working in such organizations requires a sensitivity and empathy with various groups of individuals from other organizations and from other geographical areas. When considering the need to understand how cultures develop over time, it becomes clear that a capture of the ethical climate of an organization through a snapshot is problematic. At least, scientists will have to carry out longitudinal researches and use a comparative methodology to start understanding changes in time and space.

Considering the magnitude of the globalization, the influence of culture on ethical behavior is an increasingly important issue. We can expect different interpretations of an ethical culture depending on cultural, national/international contexts. We can apply frameworks and taxonomies to analyze the culture and to classify it.

Civil servants can find themselves managing difficult cultural challenges when working with different national cultures, as well as working with public-private partnerships and/or agencies / networks.

A managerial view of culture argues that it can be universal. A viewpoint of social scientists on culture accepts a pluralistic vision of subcultures. An integrity approaches uses internal controls and a compliance approach uses external controls to function as an ethical organization. It is assumed that the integrity approach is more effective.

Integrity and compliance can be perceived as an easy but also difficult approach at the opposite end of a spectrum. Ideally, they should complement each other, because no single person is sufficient to ensure good standards of conduct.

\section{References}

[1] Ashworth A., Responsibilities, Rights and Restorative Justice, he British Journal of Criminology, Volume 42, Issue 3, 1 June 2002, Pages 578595, https://doi.org/10.1093/bjc/42.3.578 Published: 01 June 2002

[2] Behn, R.D., Why Measure Performance? Different Purposes Require Different Measures September 2003,m Public Administration Review 63(5):586 - 606 DOI: 10.1111/1540-6210.00322

[3] Brown ME, Treviño LK, Harrison DA, Ethical leadership: A social learning perspective for construct development and testing, Academic Press, Organizational behavior and human decision processes 97 (2), 2005, 117 134.

[4] Ciulla, J.B., Ethics and leadership effectiveness, In J. Antonakis, A. T. Cianciolo, \& R. J. Sternberg (Eds.), The nature of leadership (p. 302-327). Sage Publications, Inc. [5] Knights D, O'Leary M., Leadership, Ethics and Responsibility to the Other, Journal of Business Ethics volume 67, pages125-137 (2006)

[6] Paine, L.S. (1994). Managing for organizational integrity. Harvard Business Review. 17-106.

[7] Trevino L., K., Ethical decision making in organizations: A person-situation interactionist model, The Academy of Management Review, 11(3), 601617. https://doi.org/10.2307/258313 